4. Cleland E.E., Chuine I., Menzel A., Mooney H.A., Schwartz M.D. Shifting plant phonology in response to global change. Trends in Ecology and Evolution. 22. 2007. P. 357-365.

5. Van Ort P.A.J., Timmermans B.G.H., Meinke H., Van Ittersum M.K. Key weather extremes affecting potato production in the Netherlands. European Lournal of Agronomy. 37. 2012. P. 11-22.

6. David Levy, Richard E. Veilleux. Adaptation of potato to high Temperatures and Salinity. Amer. J. of Potato res. 84. 2007. P. 487-506.

DOI https://doi.org/10.30525/978-9934-26-047-6-2

\title{
GROWTH AND PHYSIOLOGICAL COMPENSATION OF MUSTARD SEEDLING AFTER DROUGHT STRESS AND REHYDRATION
}

\author{
Melnyk A. V. \\ Doctor of Agricultural Sciences, Professor \\ Professor at Department of Garden Design and Forestry \\ Sumy National Agrarian University \\ Peipei Jia \\ Ph.D. at the Department of Garden Design and Forestry \\ Sumy National Agrarian University \\ Butenko S. O. \\ Ph.D. at the Department of Garden Design and Forestry \\ Sumy National Agrarian University \\ Sumy, Ukraine
}

As a result of global climate change, drought is becoming a more frequent and increasingly severe problem [4]. Water deficit disturbs various physiological and biochemical traits and has adverse bearing on plant growth and productivity [3]. Under natural conditions, crops are often exposed to the changeable drought-rehydration environment. Drought generally inhibits plant growth and development, but a certain level of drought and rehydration can promote plant growth to compensate for damage and loss caused by stress. Compensation is an important self-regulatory mechanism used by plants to defend against environmental stresses or injuries [2]. Studies in 
soybean and Brassica carinata [3] reported that plants can exhibit compensation on root length, leaf areas, number of leaves after a certain level of drought stress and rehydration. In Artemisia halodendron, the chlorophyll content, membrane permeability, SOD and CAT activities, and the contents of the three osmoregulatory substances began to recover under moderate drought and rehydration [1]. Zhou et al. [5] found that after $6 \mathrm{~d}$ of drought stress and rehydration, the proline and soluble protein contents of the seedlings increased significantly; the MDA and soluble sugar contents and the POD activity significantly decreased, and the SOD, CAT, and APX activities significantly increased.

Mustard is widely cultivated due to its prominent economic value and unique flavor. In recent years, abiotic stresses (limited moisture supply, high transpiration, and continuous high temperature) was detrimental to the healthy growth of mustard in Ukraine. However, few studies have been reported on the physiological responses of mustard to drought and rehydration. To provide some of the missing data, we designed a study to examine the effect of drought stress and rehydration on the growth compensation, photosynthesis and antioxidant system. Our goal was to provide a better theoretical basis for drought resistance adaptability of mustard.

The variety used in the experiment was FELICIA, which provided by Sumy National Agricultural University, Ukraine. The mustard seedlings were grown in the plastic container $(40 \times 28 \times 14 \mathrm{~cm})$ with $5 \mathrm{~L}$ Hoagland's solution in the artificial climate chamber of Henan Institute of Science and Technology, China. Drought stress was induced by adding PEG. The following treatments were used: (1) CK (control), (2) $10 \%$ PEG + Hoagland's solution; (3) 15\% PEG + Hoagland's solution; (4) $20 \%$ PEG + Hoagland's solution. Samples were measured at 3, 6, and 9 days after drought treatments and on the sixth day after rehydration.

In the present study, the growth rate of fresh weight in root $(4.02 \%$ and $20.41 \%)$ and shoot $(31.57 \%$ and $44.54 \%)$ reduced significantly under moderate and severe stress during plants subjected to drought stress for 9 days, respectively. After 6 days of rehydration, growth rates of fresh weight in roots $(82.93 \%$ and $191.19 \%)$ and shoots $(172.55 \%$ and $347.58 \%)$ were higher than those before rehydration. The results showed that there was an overcompensation of roots and shoots. Drought stress induced prominent increase of SOD, POD, APX and CAT activity in roots and leaves compared to well-watered control plants, which indicated the activation of antioxidant system. After rehydration, the activities of CAT, POD and SOD in the stressed roots were higher than those in the control, but SOD, POD, APX 
and CAT activities in leaves under severe stress were significantly higher than the control and other treatments.

Our results showed that the fresh weight of roots and shoots increased rapidly and produced growth compensation after rehydration, even though drought inhibited the growth of mustard. In addition, drought and rehydration induced the increase of SOD, POD, APX and CAT activities, and the effective antioxidant system mitigated membrane damage. To some extent, it can be concluded that mustard had a strong ability to endure drought stress.

\section{References:}

1. Chen J, Zhao X, Zhang Y, Li Y, Luo Y, Ning Z, Wang R, Wang P, Cong A. (2019). Effects of Drought and Rehydration on the Physiological Responses of Artemisia halodendron. Water 11 (4):793.

2. Dong S, Jiang Y, Dong Y, Wang L, Wang W, Ma Z, Yan C, Ma C, Liu L. (2019). A study on soybean responses to drought stress and rehydration. Saudi J Biol Sci 26 (8):2006-2017.

3. Husen A, Iqbal M, Aref IM. (2014). Growth, water status, and leaf characteristics of Brassica carinata under drought and rehydration conditions. Brazilian Journal of Botany 37 (3):217-227.

4. Men Y, Wang D, Li B, Su Y, Chen G. (2018). Effects of drought stress on the antioxidant system, osmolytes and secondary metabolites of Saposhnikovia divaricata seedlings. Acta Physiol Plant 40 (11):1-14

5. Zhou X, Wang G, Liang Z, Han R. (2011). Effects of drought stress and rehydration on physiological characteristics and glycyrrhizin accumulation of glycyrrhiza uralensis fisch. Seedling. Acta Agriculturae Borealioccidentalis Sinica 20 (7):64-70. 